\title{
The Semantic Analysis of the Definite Article' Misuse by Chinese Learners of English
}

\author{
Juanjuan Geng \\ Foreign Language Department, Xianyang Normal University \\ Wenlin Road, Xianyang 712000, China \\ Tel: 86-29-3372-2436Ｅ-mail: mylovegj@163.com
}

The research is financed by Xianyang Normal University. No. 07XSYK258

\begin{abstract}
Based on Bickerton's (1981) Semantic Wheel Model, the study collected Chinese learners' performance on an article test, and then made a semantic analysis of the results. The main findings include: 1 . The two features of referentiality, namely, whether or not the noun phrase has a specific referent and whether or not it is assumed known to the hearer $([ \pm \mathrm{SR}]$ and $[ \pm \mathrm{HK}])$ have a statistically significant influence on Chinese learners' article accuracy; $[+\mathrm{SR},+\mathrm{HK}]$ and [-SR, $-\mathrm{HK}]$ are proved to be the easiest while $[-\mathrm{SR},+\mathrm{HK}]$ is the most problematic. 2. Chinese learners tend to associate the definite article with $[+\mathrm{HK}]$ contexts rather than $[+\mathrm{SR}]$ contexts, for the overuse of the definite article in [+HK] environments is significantly higher than that in $[+\mathrm{SR}]$ contexts. Finally, several suggestions on English article instruction are pointed out for teachers in college.
\end{abstract}

Keywords: English articles, Semantic contexts, Noun phrases

\section{Introduction}

It is well documented in second language studies that nonnative speakers of English have difficulty in acquiring articles and they make errors even when all other elements of the language have been mastered. Although the definite article is the most frequent morpheme (Master, 1997), the Chinese learners of English misuse it on occasions. Many Chinese researchers approached the problem from error analysis, acquisition, and pragmatics (Li jingquan\& Cai jingting, 2001; Zhu yeqiu, 2003; Yan lili, 2003; Wang jian, 2005). Only Cai jinting\& Wu yi'an (2006) analyzed the misuse of the definite article from semantic perspective. Therefore, it is worth discussing the misuse of the definite article from the semantic point of view on the basis of experimental study.

\section{Literature review}

\subsection{Semantic types}

Adopted from Bickerton's (1981) semantic classification, Huebner's (1983) classification has been the most widely used model for the analysis of English noun phrase (NP) environments and is used as well in this study. He analyzed NPs in terms of Bickerton's proposed universal features of referentiality--namely, whether or not the noun phrase has a specific referent and whether or not it is assumed known to the hearer. Hence, noun phrases are classified as plus or minus the feature of specific referent $([ \pm \mathrm{SR}])$ and plus or minus the feature of assumed known to the hearer $([ \pm \mathrm{HK}])$. The four combinations of the two binary features constitute what Huebner calls semantic types. In Huebner's model, the use of English articles is determined by the semantic function of the NP in discourse. Each NP belongs to one of the four types/categories, permitting us to assign a semantic function to each NP. To determine with what accuracy articles are used, one considers what is used in Standard English. Table 1 presents a classification system in terms of the two binary features.

\subsection{Previous studies}

Huebner (1985) analyzed new data from the informant of his previous study from the perspective of the semantic features of $[+\mathrm{SR},+\mathrm{HK}]$ and discourse features of topic continuity. Consistent with his previous study, he observed early "flooding" of the definite article in all noun features and found that the-flooding receded first in [-SR, $-\mathrm{HK}]$ feature and later in $[+\mathrm{SR},-\mathrm{HK}]$ feature, while the subject continued to use the in $[+\mathrm{SR},+\mathrm{HK}]$ and $[-\mathrm{SR},+\mathrm{HK}]$ features. The results suggested that L2 learners initially might associate the with the feature of [+HK], in contrast to children learning the English article system as part of their L1. 
Consistent with Huebner, subjects used the considerably in [+HK] contexts in Master's study $(1987,1988)$. Master's pseudo-longitudinal study consisted of 20 adult L2 learners, who were drawn from three groups whose native language does not have article system ([-ART]: Chinese, Japanese and Russian) and two groups whose mother tongue does have article system ([+ART]: Spanish and German). An informal interview was conducted to elicit spontaneous speech from each subject. Consistent with $G e$ 's use of the definite article in [+HK] contexts in Huebner (1983), the [-ART] group used the considerably in [+HK] contexts, and used $a$ or $\varnothing$ to a greater extent in [-HK] contexts. Analysis also revealed that articles appeared to be acquired differently depending on whether or not they occurred in the learner's first language. [+ART] speakers appeared to be approximately one level ahead of [-ART] speakers, the first language thus had a clear influence on early approximations to the target language, though this L1 influence usually decreased with increasing L2 proficiency. Although Chinese subjects were included in his study, their ages were ranged from 25-63 years, older than the subjects in the present study.

Whereas in Parrish's (1987) experiment, the was restricted to [+SR] for the was remarkably lacking in [-SR] contexts. Other studies, including Takahashi (1997), Thomas (1989), claimed that the was initially associated with $[+\mathrm{SR}]$ rather than $[+\mathrm{HK}]$ contexts. Thomas (1989) involved both the speakers of [+ART] languages and [-ART] languages in the story-telling task and presented a different claim from those of Huebner (1985). Thomas' findings included the following three observations: unlike L1 learners, ESL learners did not exhibit early and accurate control of $a$ in [-SR, - HK] contexts, and the in [+SR, +HK] contexts; the most common errors by L2 learners across proficiency levels were over-generalization of zero article; both L1 child acquirers and L2 learners over-generalized the in first-mention contexts $([+\mathrm{SR},-\mathrm{HK}])$ but not in $[-\mathrm{SR},-\mathrm{HK}]$ contexts. Thomas hypothesized that these results could be attributed to the fact that both L1 and L2 learners initially associate the with the feature [+SR]. Data did not show signs of the-flooding. In addition, Thomas pointed out that Huebner (1983) and Master's (1987) claim of the initial association of the with [+HK] contexts needed careful consideration because their findings were heavily dependent on high frequency of the in $[+\mathrm{SR},+\mathrm{HK}]$ contexts, but short of support from the rarely produced generic NPs in [-SR, +HK] contexts.

The Chinese scholars Cai Jinting \& Wu Yi'an (2006) collected data from cloze test and corpus. They examined the relationship between three characteristics of noun phrases, (namely specific reference, hearer's knowledge, countability) and the use of articles, as well as the influence of tasks and absence of the article system in Chinese. They found that the three characteristics of noun phrases exerted significant influence on the occurrence and accuracy of articles. The subjects used articles more accurately in composition than in cloze test, and their substitution zero article for definite and indefinite article may be due to L1 transfer and economic principle.

In fact, inconsistency in article acquisition has been long existed in literature. Bearing these differences in mind, this study intends to solve the following two hypotheses:

1. Different semantic features have influence on the accurate use of articles.

2. The definite article is over-generalized more in $[+\mathrm{HK}]$ than in $[+\mathrm{SR}]$ contexts.

\section{Study design}

The subjects in this study were 85 Chinese college learners of English (35 males and 50 females, aged 19-23) sampled from non-English majors. They have to complete an article-focused test composed of 54 obligatory uses of the articles, which was adopted from Master (1994) and Ekiert (2004).

As for the validity, Master's (1994) article test was considered to be a legitimate instrument for this study for the following two reasons. First, the test covers the entire range of article usage, including the four semantic categories. Second, the test was designed to test article usage for non-native speakers of English, so it was also suitable for Chinese learners.

As for the reliability of the test, the KR-21 reliability estimate was .789 in the pilot study. Therefore, the test adopted in present study was valid and reliable.

Data collected from the test was analyzed in two aspects: As for the accuracy of articles in different semantic types, two-way analysis of variance (ANOVA) was conducted. As for the overuse of articles, paired-sample T test was carried out to test whether the differences of the in $[+\mathrm{SR}]$ and $[+\mathrm{HK}]$ contexts were statistically significant. All the statistical analysis will be done by using the statistical software of SPSS 11.0.

\section{Results and discussion}

\subsection{Semantic contexts and accuracy of articles}

Firstly, the results of one-way ANOVA for the semantic feature effect on the accurate use of articles are found to be statistically significant at .05 level $(\mathrm{F}=69.75, \mathrm{p}<.05)$. Thus, the semantic feature is a variable affecting the 
subjects' correct choice of articles.

Multiple comparisons are made in order to determine which features significantly differ from each other. The results of between-feature comparisons of accuracy are shown in Table 2. The data illustrates that the difference among four semantic features is significant at .05 level except that between Type 2 and 4 , which show no such significant difference. Thus the sequence of accuracy rate across four semantic contexts can be drawn out: Type 4 = Type $2>$ Type $3>$ Type 1 . The accuracy order means Type 1 maybe the most difficult contexts for Chinese learners, while Type 4 and 2 proved to be the easiest.

Therefore, hypothesis one is partly upheld. There proves to be significant difference among four semantic contexts except between Type 2 and 4, and Type 1 turns out to be the most difficult while Type 4 and 2 is the least problematic.

\subsection{Semantic contexts and overuse of the definite article}

Paired-sample $\mathrm{T}$ test is conducted to test whether the difference in overuse rate between [+SR] and [+HK] contexts is statistically significant. As revealed in Table 3, $\mathrm{t}=-9.96$, which is significant at .01 level (two-tailed).

Thus, the overuse rate in $[+\mathrm{HK}]$ is statistically higher than in $[+\mathrm{SR}]$ environments. Hypothesis two, which claims the definite article is associated with $[+\mathrm{HK}]$ feature is supported, at least in present study.

As opposed to Huebner (1983) and Master (1987), Parrish (1987) and Thomas (1989) found the was associated with [+SR] contexts, rather than $[+\mathrm{HK}]$ contexts, for their subjects restricted the to $[+\mathrm{SR}]$ contexts and rarely applied to [-SR] contexts. Cai Jinting \& Wu Yi'an (2006) suggested that overuse of the in [+SR, -HK] was significant in cloze test, but rare in compositions. Thomas (1989) pointed out Huebner (1983) and Master's (1987) claim needed further examination because of over-reliance on scarce [-SR, +HK] environments in the production of L2 learners. Such problems are avoided in present study as the items are distributed nearly equally among four semantic contexts. Huebner (1983) and Master's (1987) claim is re-confirmed by the study.

\section{Pedagogical Implications based on this study}

The main findings of this study will shed light on the instruction of English article system to Chinese college learners. Several suggestions are offered for both teachers and learners.

First, more attention needs to be paid to the systematic and formal instruction and learning of English articles. The findings clarified in this research suggest that English article system is problematic for all Chinese learners, regardless of proficiency level. Moreover, Chinese college teachers should change their old belief that articles are unimportant words that need not be taught, for they have been introduced in high school.

Second, the generic usage of English articles should be reinforced. It was made clear that the generic usage of articles posed great difficulty for learners and it was neglected in texts (Whitman, 1974).

Third, the concept of countability needs further clarification for Chinese learners whose language lacks the distinction between countable nouns and uncountable nouns.

In a sum, the complex nature of English article system requires that they be introduced gradually over a long period of time and they can not possibly be taught in a single lesson. Nevertheless, the articles can and should be taught (Master, 1997). It is possible that the situation will improve if the pedagogical implications suggested above are incorporated in courses for Chinese college learners of English.

\section{References}

Bickerton, D. (1981). Roots of Language. Ann Arbor: Karoma Publishers.

Butler. Y. G.. (2002). Second Language Learners' Theories on the Use of English Articles: An Analysis of the Metalinguistic Knowledge Used by Japanese Students in Acquiring the English Article System. Studies in Second Language Acquisition, 24, 451-480.

Cai, Jinting \& Wu, Yi'an. (2006). Chinese College Learners' Use of English Articles. Foreign Language Teaching and Research, 38, 243-250.

Ekiert, M. (2004). Acquisition of the English Article System by Speakers of Polish in ESL and EFL Settings. Working Papers in TESOL\& Applied Linguistics, 4,1-23.

Huebner, T. (1983). A Longitudinal Analysis of the Acquisition of English. Ann Arbor, MA: Karoma Press.

Huebner, T. (1985). System and Variability in Interlanguage Syntax. Language Learning, 35, 141-163.

Li, Jingquan \& Cai, Jinting. (2001). Misuse of Articles in Writing by Chinese Learners---A Study Based on Corpus. Journal of PLA University of Foreign Languages, 24, 58-62. 
Master, P. (1987). A Cross-Linguistic Interlanguage Analysis of the Acquisition of the English Article System. Unpublished doctoral dissertation, UCLA.

Master, P. (1988a). Teaching the English Article System (Part 1). English Teaching Forum, 26, 2-7.

Master, P. (1988b). Teaching the English Article System (Part 2). English Teaching Forum, 26, 18-25.

Master, P. (1994). The Effect of Systematic Instruction on Learning the English Article System. In T. Odlin (Ed.).

Perspectives in Pedagogical Grammar. Cambridge, U.K.: Cambridge University Press, pp. 99-122.

Master, P. (1997). The English Article System: Acquisition, Function and Pedagogy. System, 25, 215-232.

Parrish, B. (1987). A New Look at Methodologies in the Study of Article Acquisition for Learners of EFL. Language Learning, 37, 361-383.

Takahashi, T. (1997). Japanese Learners' Acquisition and Use of the English Article System. Edinburgh Working Papers in Applied Linguistics, 8, 98-110.

Thomas, M. (1989). The Acquisition of English Articles by First and Second Language Learners. Applied Psycholinguistics, 10, 335-355.

Wan, Jian. (2005). The Acquisition of Non-generic Usage of English Articles by Chinese Learners. Foreign Language Teaching, 26, 22-26.

Whitman, R.L. (1974). Teaching the Articles in English. TESOL Quarterly, 8, 253-262.

Yan, Lili. (2003). Acquisition of articles by Chinese learners. Foreign language teaching and research. 25, 210-214.

Zhu, Yeqiu. (2003). A Survey on Chinese Learners' Mastery of English Articles. Foreign Language Teaching and Research. 18, 206-209.

Table 1. Environment and examples for the semantic categories $[ \pm \mathrm{SR}, \pm \mathrm{HK}]$

\begin{tabular}{|c|c|c|c|}
\hline $\begin{array}{l}\text { Category/ } \\
\text { Feature }\end{array}$ & Environment & Articles & Examples \\
\hline $\begin{array}{l}\text { Type } 1 \\
{[-\mathrm{SR},+\mathrm{HK}]}\end{array}$ & Generic nouns; & $\mathrm{a}$, the, $\varnothing$ & $\begin{array}{l}\text { A paper clip comes in handy. } \\
\text { The Grenomian is an } \\
\text { excitable person. } \\
\varnothing \text { Fruit flourishes in the } \\
\text { valley. }\end{array}$ \\
\hline $\begin{array}{l}\text { Type } 2 \\
{[+\mathrm{SR},+\mathrm{HK}]}\end{array}$ & $\begin{array}{l}\text { Referential definites; } \\
\text { Previous mention; } \\
\text { Specified by entailment; } \\
\text { Specified by definition; } \\
\text { Unique in all contexts; } \\
\text { Unique in a given } \\
\text { context; }\end{array}$ & The & $\begin{array}{l}\text { Pass me the pen. } \\
\text { The idea of coming to the } \\
\text { US was... } \\
\text { I found a book. The book } \\
\text { was... } \\
\text { The first person to walk on } \\
\text { the moon... }\end{array}$ \\
\hline $\begin{array}{l}\text { Type } 3 \\
{[+\mathrm{SR},-\mathrm{HK}]}\end{array}$ & $\begin{array}{l}\text { Referential indefinites; } \\
\text { First-mention nouns; }\end{array}$ & $\mathrm{a}, \varnothing$ & $\begin{array}{l}\text { Chris approached me carried } \\
\text { a dog. } \\
\text { I keep sending } \varnothing \text { messages } \\
\text { to him. } \\
\text { I always drink } \varnothing \text { water with } \\
\text { my meal. }\end{array}$ \\
\hline $\begin{array}{l}\text { Type } 4 \\
{[-\mathrm{SR},-\mathrm{HK}]}\end{array}$ & $\begin{array}{l}\text { Non-referential nouns; } \\
\text { Attributive indefinites; } \\
\text { Non-specific indefinites; }\end{array}$ & $\mathrm{a}, \varnothing$ & $\begin{array}{l}\text { Alice is an accountant. } \\
\text { I guess I should buy a new } \\
\text { car. } \\
\varnothing \text { Foreigners would come up } \\
\text { with a better solution. }\end{array}$ \\
\hline
\end{tabular}


Table 1, adopted from Thomas (1989), Huebner (1985), and Butler (2002), presents a classification system in terms of the two binary features, $[ \pm \mathrm{SR}, \pm \mathrm{HK}]$. Nouns classified as $[-\mathrm{SR},+\mathrm{HK}]$ are generic nouns and are marked with $a$, the, $\varnothing$. Nouns classified as [-SR,-HK] are non-referential nouns and are marked with $a$, $\varnothing$. These articles are used with nouns that name a class to which another noun is asserted to belong or that refer to an unspecified member of a class (Thomas, 1989). The [+SR,-HK] feature includes referential indefinite nouns, which are marked with $a, \varnothing$. The referent is identifiable not to the hearer but to the speaker, who is entering the noun into the discourse for the first time. Finally, the $[+\mathrm{SR},+\mathrm{HK}]$ feature includes referential definite nouns which are previously mentioned, are specified by entailment or definition, and are unique in all contexts or in a given context, etc (Thomas, 1989). These nouns are marked with the.

Table 2. Multiple comparisons of means among semantic contexts

\begin{tabular}{|rr|r|r|}
\hline \multicolumn{1}{|c|}{ Semantic contexts } & $\begin{array}{c}\text { Mean } \\
\text { difference }\end{array}$ & \multicolumn{1}{c|}{ Sig. } \\
\hline$[-\mathrm{SR},+\mathrm{HK}]$ & {$[+\mathrm{SR},+\mathrm{HK}]$} & $-.2732 *$ & .000 \\
& {$[+\mathrm{SR},-\mathrm{HK}]$} & $-.1807 *$ & .000 \\
& {$[-\mathrm{SR},-\mathrm{HK}]$} & $-.2763 *$ & .000 \\
& & & \\
\hline$[+\mathrm{SR},+\mathrm{HK}]$ & {$[-\mathrm{SR},+\mathrm{HK}]$} & $.2732 *$ & .000 \\
& {$[+\mathrm{SR},-\mathrm{HK}]$} & $.0924 *$ & .001 \\
& {$[-\mathrm{SR},-\mathrm{HK}]$} & -.0031 & .999 \\
\hline$[+\mathrm{SR},-\mathrm{HK}]$ & {$[-\mathrm{SR},+\mathrm{HK}]$} & $.1807 *$ & .000 \\
& {$[+\mathrm{SR},+\mathrm{HK}]$} & $-.0924 *$ & .001 \\
& {$[-\mathrm{SR},-\mathrm{HK}]$} & $-.0955^{*}$ & .000 \\
\hline$[-\mathrm{SR},-\mathrm{HK}]$ & {$[-\mathrm{SR},+\mathrm{HK}]$} & $.2763 *$ & .000 \\
& {$[+\mathrm{SR},+\mathrm{HK}]$} & .0031 & .999 \\
& {$[+\mathrm{SR},-\mathrm{HK}]$} & $.0955^{*}$ & .000 \\
\hline
\end{tabular}

*. The mean difference is significant at the .05 level.

The multiple comparison of the accuracy on each semantic type is shown in Table 2. Subjects got lowest score in $[-\mathrm{SR},+\mathrm{HK}]$ context, while they perform best in $[-\mathrm{SR},-\mathrm{HK}]$ context, following by $[+\mathrm{SR},+\mathrm{HK}],[+\mathrm{SR},-\mathrm{HK}]$.

Table 3. T-test in overuse percent between $[+\mathrm{SR}]$ and $[+\mathrm{HK}]$ contexts

\begin{tabular}{|l|c|c|c|c|c|c|}
\hline \multirow{2}{*}{} & \multicolumn{3}{|c|}{ Paired Differences } & $\mathrm{t}$ & df & $\begin{array}{c}\text { Sig. } \\
\text { (2-tailed) }\end{array}$ \\
\cline { 2 - 5 } & Mean & $\begin{array}{c}\text { Std. } \\
\text { Deviation }\end{array}$ & $\begin{array}{c}\text { Std. Error } \\
\text { Mean }\end{array}$ & & & \\
\hline $\begin{array}{l}\text { Overuse percent in [+SR]---- } \\
\text { Overuse percent in [+HK] }\end{array}$ & -.2695 & .24940 & .02705 & -9.963 & 84 & .000 \\
\hline
\end{tabular}

As revealed in Table 3, the overuse percent in [+SR] is less than that in [+HK] context. The standard deviation is .24940 , and $\mathrm{t}=-9.963$ which is significant at .01 level ( 2 tailed). That implies the subjects tend to associate the definite article with $[+\mathrm{HK}]$ feature. 